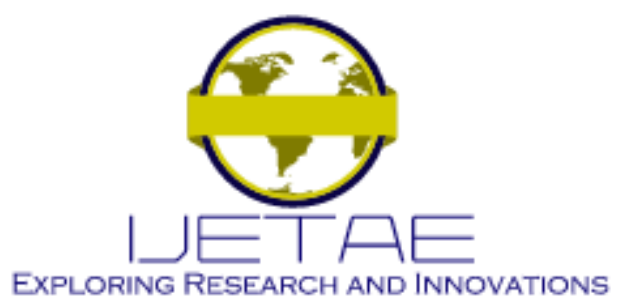

International Journal of Emerging Technology and Advanced Engineering

Website: www.ijetae.com (E-ISSN 2250-2459, Scopus Indexed, ISO 9001:2008 Certified Journal, Volume 12, Issue 02, February 2022)

\title{
Influence of Built-in Electric Fields on the Gallium Phosphide- Based LEDs Hardness to Gamma-Ray Irradiation
}

\author{
Kseniya Orlova ${ }^{1}$, Alexander Gradoboev ${ }^{2}$, Anastasiya Simonova ${ }^{3}$

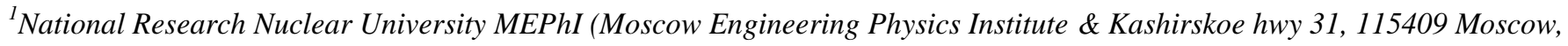 \\ Russia \\ ${ }^{2}$ Tomsk Polytechnic University \& Lenina av. 30, 634050 Tomsk, Russia \\ ${ }^{3}$ Scientific and Engineering Centre for Nuclear and Radiation Safety\& M. Krasnoselskaya 2/8, b.5, 115409 Moscow, Russia
}

\begin{abstract}
The paper shows the influence of the power supply mode (without - "M-B" and with the separation of electron-hole pairs - "M-CC" generated by irradiation in the built-in electric field of the pn-junction of light-emitting diodes) on the LEDs emission power changing under gamma quanta. LEDs were based on monocrystalline gallium phosphide. The maximum radiation wavelength is at $655 \mathrm{~nm}$. It is shown that the division of electron-hole pairs in the field of a built-in pn-junction makes it possible to significantly increase their stability. The emission power decreasing as a result of irradiation with gamma quanta is described in three stages. The first stage is due to the radiation-stimulated rearrangement of the first initial defect (complex of defects) of the first type. At the second stage, the decrease in power is due to the radiation-stimulated rearrangement of the initial defect (complex of defects) of the second type. In this case, the separation of electron-hole pairs generated during irradiation leads to a significant LEDs hardness increasing to the of gamma quanta action. At the third stage, the emission power decreasing is due to the only radiation defect's introduction. For each of the identified stages of emission power reducing, empirical relationships, that describe the emission power changing with the radiation dose increasing and damage factors for the irradiation modes are numerically determined.
\end{abstract}

Keywords - Radiation hardness, LEDs, GaP, gamma quanta, emission power.

\section{INTRODUCTION}

Light-emitting diodes, laser diodes and screens operating on the electroluminescence principles have become wide spreading. The application scope of these optoelectronic devices encompasses diverse fields of different control and measuring equipments, lighting equipments, as well as nuclear sector and space-based technologies. Devices can be exposed to various types of ionizing radiation after application in these fields. Therefore, it would require the knowledge about influence pattern of ionizing radiation over parameters of LEDs.
A wide range of LEDs based on monocrystalline GaP has been mastered for a long time in the conditions of serial production [1-4]. They still remain in demand by a wide variety of consumers at the same time. This is primarily due to the circumstance that the use of various alloying additives allows GaP cultivation to obtain materials for LEDs operating in a wide range of the visible optical spectrum region. Moreover, red LEDs use in a great many areas[4,5]. Red color is very convenient for indication. Therefore, it allows to prepare multi-color system for depicting information.

Nowadays knowledge about the impact of ionizing irradiation on the LEDs is fragmented [6-9]. It is necessary to know the basic patterns of changes in the key factors of the LEDs during ionizing radiation in order to guarantee the required parameters of ionizing radiation resistance [1012]. It is known from literature data that the availability of built-in and/or external electric fields could result to a noticeable change in the rate of introduction of various defects into the active layers of semiconductor devices [1314]. However, there are practically no studies on the effect of the LEDs powering mode on their resistance during irradiation.

The purpose of the work is to research the effect of the power supply mode on the resistance of the LEDs based on the monocrystalline $\mathrm{GaP}$ with a wavelength of $655 \mathrm{~nm}$ to gamma-quanta irradiation by ${ }^{60} \mathrm{Co}$.

\section{MATERiAl AND Methods}

LEDs based on $\mathrm{GaP}$ with an effective wavelength of 655 $\mathrm{nm}$ are research objects is due to the circumstance that they are characterized by presence the radiative recombination of all main types.

Let us consider in more detail the preparation of the LEDs. There are crystallization of $\mathrm{GaP}$ in a zinc blende with an edge of an elementary cubic cell of $5.4506 \AA$. 


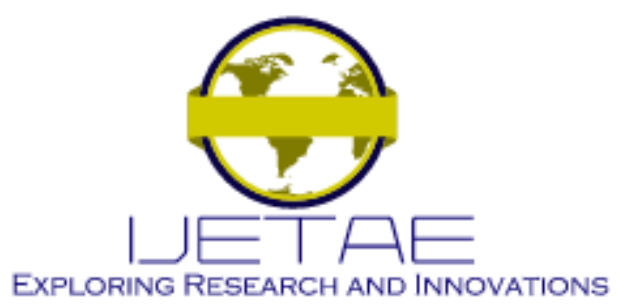

International Journal of Emerging Technology and Advanced Engineering Website: www.ijetae.com (E-ISSN 2250-2459, Scopus Indexed, ISO 9001:2008 Certified Journal, Volume 12, Issue 02, February 2022)

The nuclei of the GaP lattice elements have the shortest distance between the centers that is equals to $2.36 \AA$. This distance is the sum of the atomic radii $\mathrm{P}(1.1 \AA)$ and $\mathrm{Ga}$ $(1.26 \AA)$ [5].

$\mathrm{GaP}$ classifies as non-band gap semiconductors in which radiative recombination becomes through defect centers. It is because the interband transitions occurring probability with momentum conservation is negligible[15]. Therefore, the optically active isoelectronic impurity introduction into the $\mathrm{GaP}$ makes it possible to significantly increase the probability of radiative recombination in a semiconductor.

Industrial production of monocrystalline $\mathrm{GaP}$ was carried out in two stages. First of 11, it was synthesis. There were production of large polycrystalline ingots and cultivation of single crystals by the Chokhralsky method from a melt located under a layer of flux. Monocrystalline $\mathrm{GaP}$ are divided into several types according to their parameters. Single crystals of the $n$-type are doped with Te or S or are not doped with anything. Single crystals of the $p$-type are doped with $\mathrm{Zn}$. Single crystals of high-resistance $\mathrm{GaP}$ are doped with chromium or other impurities with deep energy of occurrence. The remarkable thing is that due to the growth conditions (high temperature, high back pressure $\mathrm{P}$, presence of flux, absence of resistant container materials), GaP single crystals are marked by a high level of ruleless impurities $\left(\sim 5 \times 10^{16}-1 \times 10^{17} \mathrm{~cm}^{-3}\right)$, as well as a high dislocation density (more than $10^{4} \mathrm{~cm}^{-2}$ ) [5].

When $\mathrm{GaP}$ plates were grown from a solution, zinc and oxygen, that was obtained from $\mathrm{Ga} 2 \mathrm{O} 3$, were used as alloying impurities [15].

Therefore, crystals were made, and then mounted in the TO-18 case. The schematic diagram of the LEDs based on a monocrystalline $\mathrm{GaP}$ is shown in Figure 1. The value of the direct operating current reached $100 \mathrm{~mA}$ in continuous power supply mode, and the supply voltage did not exceed $2.0 \mathrm{~V}$. The maximum wavelength of the LEDs emissive power is in the range of about $655 \mathrm{~nm}$.

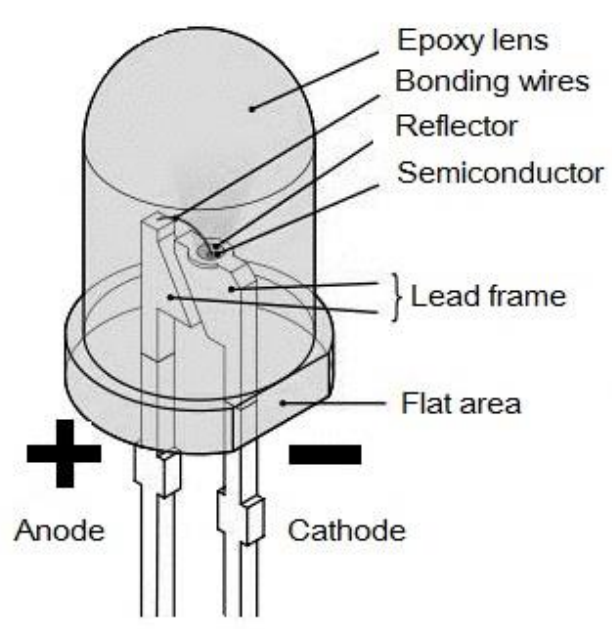

Fig. 1 Typical design of LEDs based on GaP.

A experimental facility with a dose rate of $(100-200)$ Gy/s was used for the experiment. The active element in this installation is the isotope $\mathrm{Co}^{60}$ with an effective gamma-quanta energy of $1.25 \mathrm{MeV}$. We used data on the activity of the equipment at the time of the experiment and correlated the radiation dose with the exposure time. The supply of external electrical power can make a substantial contribution to the change in the radiation hardness of semiconductor devices $[13,14]$ and lead to the annealing of irradiation defects. Therefore, irradiation of the original structures and devices in all cases was carried out without the imposition of external electric fields. The measurement error was no more than $3 \%$ in the entire volume of experimental data.

Before and after irradiation, the watt-ampere $(W-I)$ and volt-ampere $(V-I)$ characteristics of the LEDs were measured. The measurements were carried out under normal conditions in a photometric ball using a measuring complex that allowed the direct voltage measuring of the LEDs in the range from 0.0 to $5.0 \mathrm{~V}$ for the range of direct currents $(0-500) \mathrm{mA}$ in increments of $1 \mathrm{~mA}$. 


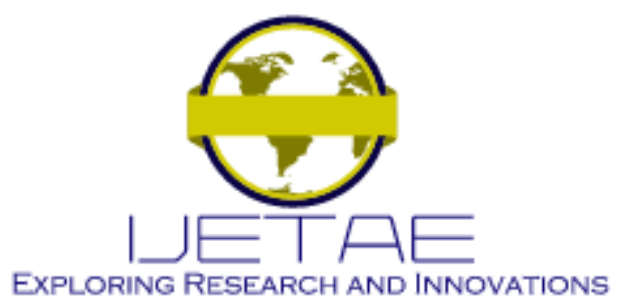

International Journal of Emerging Technology and Advanced Engineering Website: www.ijetae.com (E-ISSN 2250-2459, Scopus Indexed, ISO 9001:2008 Certified Journal, Volume 12, Issue 02, February 2022)

While the error of setting the direct current from the set level is $\pm 3 \%$, and the measuring error of LEDs emissive power is $\pm 5 \%$.

However, the electrical leads were short-circuited (MCC) during irradiation for the first batch LEDs. In this case, the built-in electric field of the $p$ - $n$ junction of the LEDs is closed. Electron-hole pairs generated by gamma-quanta are separated in the area of spatial charge (the area of the $p-n$ transition of the LEDs). While the separation of electronhole pairs does not occur in the neutral region of the LEDs. The electrical leads were opened (M-B) in the second batch of LEDs. In this case, the spatial charge region is not formed and the separation of electron-hole pairs generated by gamma quanta is not occurred. Comparison of the research results of the LED batches allow us to conclude about the influence contribution of the built-in electric field of the $p$ - $n$ junction of the LEDs in its hardness to gammaquanta. In addition, the research of changes in the $V-I$ shape depending on the radiation dose allow us to conclude about the effect of the operating current density on the hardness of the LEDs to gamma-quanta irradiation during further operation.

As a result of preliminary studies, it was found that the optical lens material used for the LEDs production did not make an additional change in the light output power of the LEDs under gamma-quanta irradiation in the radiation dose range used. This suggests that the changes in light output power observed as a result of gamma-quanta irradiation is only due to changes in the lighting characteristics of the active element of the LEDs.

\section{RESULTS AND DISCUSSION}

Firstly, we look at a typical $W-I$ for the original LEDs (Figure 2) constructed in linear coordinates (Figure 2a) and in double logarithmic coordinates (Figure 2b). Note that the representation of $W-I$ in linear coordinates is practically generally accepted [16-19].
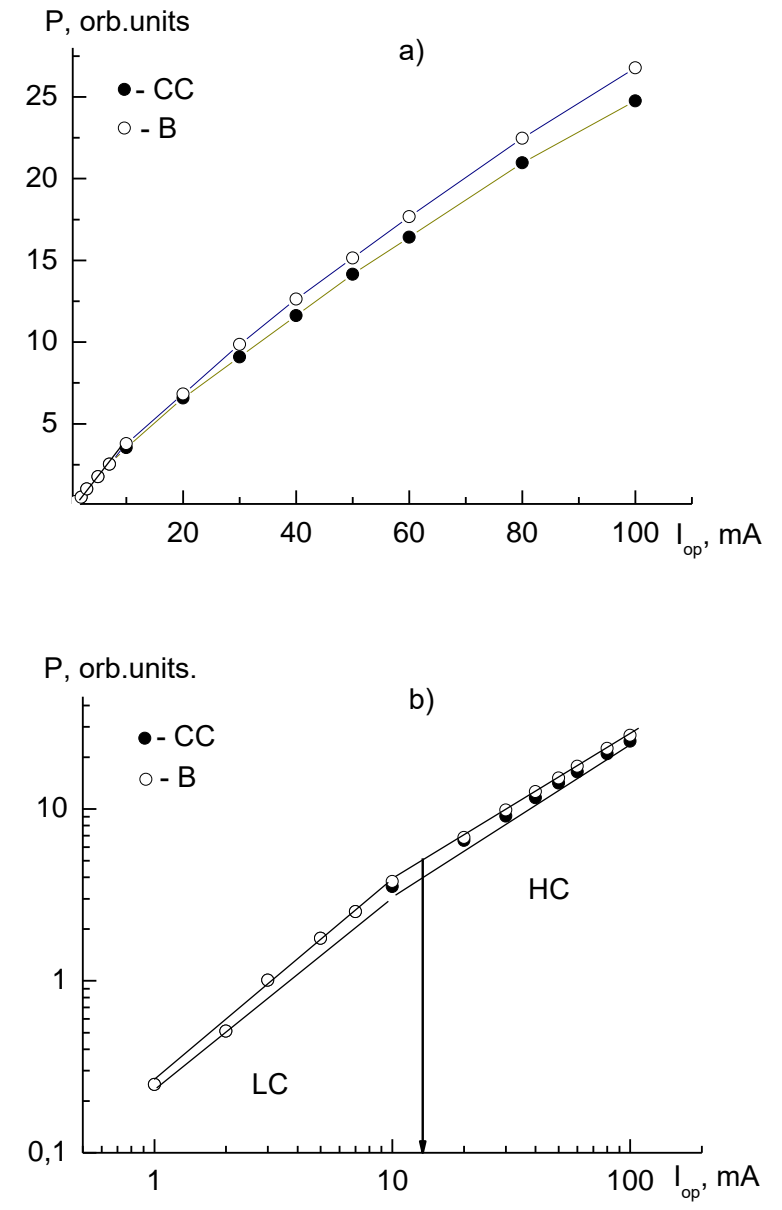

Fig. 2

Fig.2 Typical W-I characteristic of initial LEDs in linear coordinates (a) and in double logarithmic coordinates: LC area of low operating currents; HC - high operating currents area respectively; symbols - experimental data; calculation lines according to the formula (1); vertical arrow - the border between the chosen areas of the operating current. 


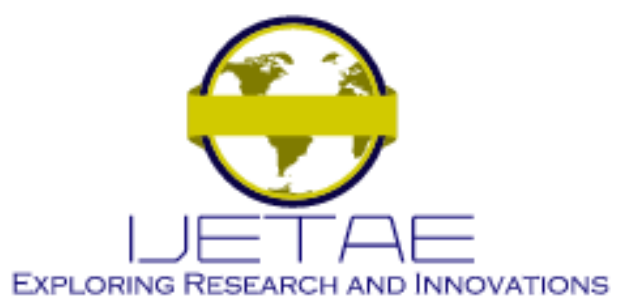

International Journal of Emerging Technology and Advanced Engineering Website: www.ijetae.com (E-ISSN 2250-2459, Scopus Indexed, ISO 9001:2008 Certified Journal, Volume 12, Issue 02, February 2022)

It can be concluded that the LEDs has a typical $W-I$ for this type of LEDs based on the analysis of the dependence presented in Figure 2a. It can be characterized as a dependence with pronounced nonlinearity for a given range of operating currents. In addition, it can be concluded that the average values of the $W-I$ for the LEDs batches did not differ significantly.

On the other hand, if the $W-I$ of the LEDs is constructed in double logarithmic coordinates (Figure 2b), it can be seen that this dependence permits us to obtain additional important information. These results consent us to distinguish two characteristic areas of operating currents (the low current region (LC) and the high current region (HC)). It is shown that each area is characterized by its own dependence of the light output power on the operating current of the LEDs.

Therefore, the W-I analysis of the original LEDs illustrated the presence of two characteristic areas of operating currents: low and high currents. Furthermore, each area is characterized by its own dependence of the LEDs light output power on the operating current. The revealed patterns remain constant when radiation dose increases.

The light output power dependence of the LEDs on the operating current value can be governed by the following relation:

$$
P=\alpha \cdot S_{p h} \cdot I_{A} \cdot\left(I_{o p}\right)^{\beta}
$$

where $P$ is the LEDs light output power; $\alpha$ is the proportionality coefficient; $S_{p h}$ is the sensitivity of the photodiode in the given wavelength range $[\mu \mathrm{A} / \mathrm{mW}] ; I_{A}$ is the amplitude value of the photocurrent; $I_{o p}$ is the operating current of the LEDs; $\beta$ is the slope of the $W-I$ in the selected area of the operating currents. At the same time, each of the selected areas of the operating currents is characterized by its own value of the proportionality coefficient $\alpha$ and its own slope of the $W-I \beta$.

A range of high currents is most often used as an working value during the design and operation of the LEDs. Therefore, the main attention is focused on the analysis of $W-I$ changes in the high operating currents field in this research. Figure 3 shows the $W-I$ changes in the high current region for the research LED batches.

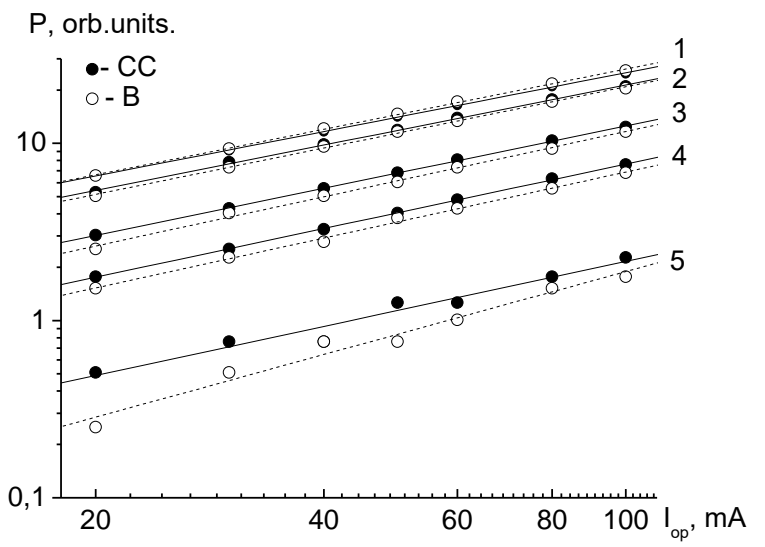

Fig.3 Change in W-I characteristics in the $\mathrm{HC}$ area $\mathrm{M}-\mathrm{CC}$ and M-B during irradiation with gamma quanta: 1 - $D \gamma=0 ; 2$ - D $\gamma=9 \cdot 10^{3}$ $\mathrm{Gy} ; 3-\mathrm{D} \gamma=1.46 \cdot 10^{5} \mathrm{~Gy} ; 4-\mathrm{D} \gamma=5.5 \times 10^{5} \mathrm{~Gy} ; 5-\mathrm{D} \gamma=2 \cdot 10^{6} \mathrm{~Gy}$.

It can be seen the following changes when dose of gamma-quanta irradiation increases. There is not only a decrease light output power of the LEDs, which can be described by a change in the proportionality coefficient $\alpha$. However, there is a change in the slope of the W-I. At the same time, LEDs from the batch with short-circuited electrical leads have higher radiation resistance. Therefore, the irradiation mode of LEDs has significant impact to their radiation hardness.

Let us consider in more detail the change in the LEDs emission power during gamma quanta irradiation. The light output power is measured at an operating current of $50 \mathrm{~mA}$. This power supply mode is recommended during operating of the LEDs. These results are represented in Figure 4. The light output power value is measured after irradiation and normalized to its value for the original LEDs. Despite the slight variation in the original $W-I$, the observed changes in the $W-I$ may differ significantly. That is observed for the results presented in Figure 4. 


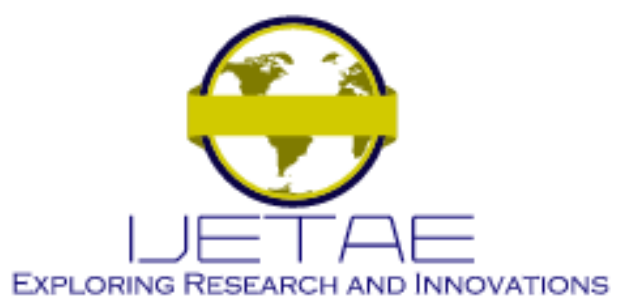

International Journal of Emerging Technology and Advanced Engineering

Website: www.ijetae.com (E-ISSN 2250-2459, Scopus Indexed, ISO 9001:2008 Certified Journal, Volume 12, Issue 02, February 2022)


Fig. 4

Fig.4 Change in the emission power M-CC (a) and M-B (b), measured at an operating current of $50 \mathrm{~mA}$, with an increase in the dose of irradiation with gamma quanta. Vertical arrows denote the limiting radiation doses separating the selected stages of the LEDs light output power decreasing.

The results analysis presented in Figure 4 allows us to distinguish three characteristic stages of decreasing the LEDs light output power during gamma-quanta irradiation.
However, the identified stages of light output power decreasing are observed independently on the irradiation mode, in spite of the circumstance that the identified stages are described by their own patterns for each of the LED batches. We have previously observed similar experimental results for LEDs based on other different materials when they were irradiated by fast neutrons and gamma-quanta $[18,19]$.

In this case it can be expected that the first stage of light output power decreasing (see stage I, Figure $2 \mathrm{a}, \mathrm{b}$ ) is resulting from radiation-stimulated restructuring of the original defective structure (first type defect or/and complex of defects). This assumption is supported by the fact that this stage is characterized by saturation. This is feasibly owing to the concentration the defect or/and complex of defects is limited. It means that an addition of an existing defect is required in this process of light output power decreasing to radiation defects that are introduced at a certain rate. We observed a similar first stage earlier [20].

The decrease in the LEDs emission power in this case can be expressed as follows:

$$
\left(\frac{P_{\gamma}}{P_{0}}\right)_{\mathrm{I}}=A_{\mathrm{I}}+B_{\mathrm{I}} \cdot \exp \left(-k_{\mathrm{I}} \cdot D_{\gamma}\right)
$$

where $k_{I}$ is the damage coefficient of the LEDs at the first stage of light output power reduction, $\left[\mathrm{Gr}^{-1}\right]$. Moreover, when the damage coefficient is higher, the radiation hardness of the LEDs is lower to gamma-quanta. $A_{I}$ and $B_{I}$ are proportionality coefficients characterized the first stage. We obtained an almost identical damage coefficient and fairly close proportionality coefficients for the LEDs at the first stage. The values are shown in Table 1.

Next, we consider the proportionality coefficients $A_{I}$ and $B_{I}$ in more detail. These coefficients determine the relative contribution of the selected stages to the overall light output power decreasing of the LEDs during gammaquanta irradiation. Their sum should be equal to "1" for the normalized emission power value of the LEDs. Then the coefficient $A_{I}$ determines the relative endowment of the first stage of LEDs light output power decreasing. Furthermore, the coefficient $B_{I}$ determines the contribution of the remaining stages of light output power decreasing. The proportionality coefficients $A_{I}$ and $B_{I}$ for the LEDs are also given in Table 1. 


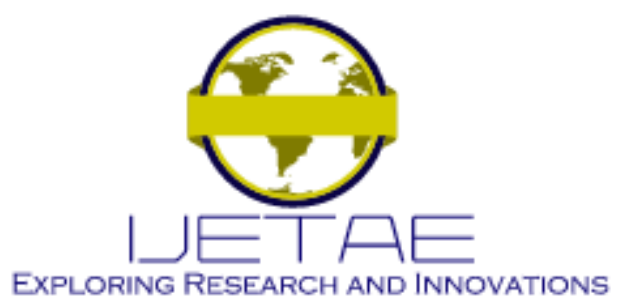

International Journal of Emerging Technology and Advanced Engineering

Website: www.ijetae.com (E-ISSN 2250-2459, Scopus Indexed, ISO 9001:2008 Certified Journal, Volume 12, Issue 02, February 2022)

The position of the boundary between the first and second stages is also shown in Table 1. Accordingly, we obtain a higher value of the boundary dose for first batch of the LEDs compared with second batch of the LEDs.

We summarize the main research results of light output power changes at the first stage. There is a slight excess of the proportionality coefficient $A_{I}$, for the first batch of the LEDs in comparison with the second batch of the LEDs at the first stage. It leads to a noticeable increase in the corresponding limit dose of gamma-quanta radiation. This can be explained by the evidence that the detachment of electron-hole pairs generated by gamma-quanta radiation in the region of spatial charge inhibits the decline in emission power at the first stage. This leads to a slight increase in the input on the first stage and to a nameworthy induction in the boundary dose, which separates the first and second stages. At the same time damage coefficient at the first stage practically does not depend on the irradiation mode.

Let us consider the second stage of light output power reduction. The change in LEDs emission power at this stage can be expressed as follow ratio:

$$
\left(\frac{P}{P}\right)_{\mathrm{II}}=\left(k_{\mathrm{II}} \cdot D_{\gamma}\right)^{-0,5}
$$

where $k_{I I}$ is the coefficient of damage during gammaquanta irradiation of the LEDs at the second stage. The damage coefficients determined in this way for the second stage are shown in Table 1.

For the second batch of the LEDs at the second stage, a damage coefficient was obtained identical to the damage coefficient that was obtained earlier for both batches at the first stage of emission power decreasing (see Table 1). This allows us to attribute the second stage to the stage of radiation-stimulated rearrangement of the own defective structure (defect or/and complex of defects of the second type). Then it can be argued that at least two initial defects (or two initial complexes of defects) in addition to radiation defects participate in the radiation-stimulated rearrangement of the initial defects during gamma-quanta irradiation.
TABLE I

W-I CHARACTERISTICS OF THE VAC FOR THE INVESTIGATED LEDS BATCHES

\begin{tabular}{|c|c|c|c|}
\hline $\begin{array}{c}\text { Power } \\
\text { reduction } \\
\text { stage }\end{array}$ & $\begin{array}{c}\text { W-I } \\
\text { Characteristic }\end{array}$ & M-CC & M-B \\
\hline \multirow{2}{*}{ I } & $\mathrm{k}_{\mathrm{I}}, \mathrm{Gy}^{1}$ & $6,25 \cdot 10^{-5}$ & $6,25 \cdot 10^{-5}$ \\
\cline { 2 - 4 } & $A_{\mathrm{I}}, \%$ & $52 \%$ & $50 \%$ \\
\cline { 2 - 4 } & $B_{\mathrm{I}}, \%$ & $48 \%$ & $50 \%$ \\
\hline $\begin{array}{c}\text { Boundary } \\
\text { between } \\
\text { stages I - } \\
\text { II }\end{array}$ & $D_{\gamma(\mathrm{IIII})}, \mathrm{Gy}$ & $1 \cdot 10^{5}$ & $4,4 \cdot 10^{4}$ \\
\hline \multirow{2}{*}{ II } & $\mathrm{k}_{\mathrm{I}}, \mathrm{Gy}{ }^{-1}$ & $4.2 \cdot 10^{-5}$ & $6.25 \cdot 10^{-5}$ \\
\cline { 2 - 4 } & $A_{\mathrm{II}}, \%$ & $31,3 \%$ & $19,5 \%$ \\
\hline $\begin{array}{c}\text { Boundary } \\
\text { between } \\
\text { stages II - } \\
\text { III }\end{array}$ & $D_{\gamma(\mathrm{II}-\mathrm{III}), \mathrm{Gy}}$ & $6.5 \cdot 10^{5}$ & $4,2 \cdot 10^{5}$ \\
\hline III & $\mathrm{K}_{\mathrm{III}}, \mathrm{Gy}{ }^{-1}$ & $1.6 \cdot 10^{-6}$ & $2.4 \cdot 10^{-6}$ \\
\cline { 2 - 4 }$\left(\mathrm{P}_{\gamma} / \mathrm{P}_{0}\right)_{\min } \cdot$ & 0,018 & 0,018 \\
\hline
\end{tabular}

On the other hand, we obtained a noticeably lower damage coefficient at the second stage for the second batch of the LEDs (see Table 1). This indicates a higher resistance of the LEDs to gamma-quanta irradiation at the second stage of light output power reduction. It can provided that the electron-hole pairs generated by gammaquanta radiation are separated. The consequence of this is a higher value of the dose limit between the second and third stages of light output power decreasing (see Table 1). 


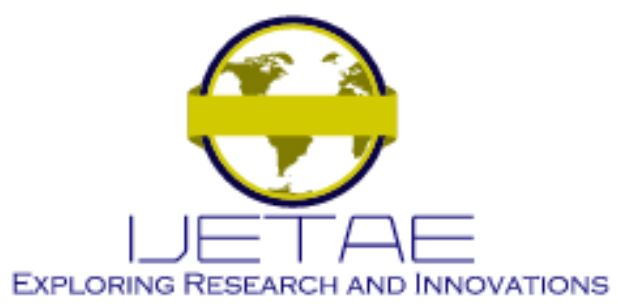

International Journal of Emerging Technology and Advanced Engineering

Website: www.ijetae.com (E-ISSN 2250-2459, Scopus Indexed, ISO 9001:2008 Certified Journal, Volume 12, Issue 02, February 2022)

The obtained research results allow us to determine the contribution of the second stage of emission power decreasing to the overall light output power decreasing for the LEDs as the difference in the normalized emission power for the identified boundaries of the second stage (see Figure 2 and Table 1).

We recapitulate the experimental results obtained for the I and II stages of the light output power reduction of the LEDs. The reasonings presented above allow us to deduce that these stages are components of the same stage caused by radiation-stimulated restructuring of the original defect structure. At the same time, each of the stage is associated with its own defect or set of defects. At the first stage, the observed reduction in light output power can be described by a similar pattern (2). At the same time, the separation of electron-hole pairs generated by gamma-quanta radiation leads to a reduction in the first stage endowment to the overall light output power reduction. Moreover, it leads to a corresponding noticeable shift of the boundary between stages I and II to the area of higher radiation doses. At the second stage, the electron-hole pairs rearrangement leads to a significant slowdown in the degradation process. Thus, the separation of the generated electron-hole pairs at these stages of light output power decreasing makes it possible to significantly increase the gamma-quanta irradiation resistance of the LEDs.

Let us consider the third stage of light output power reduction of the LEDs under irradiation by gamma-quanta. The light output power change in this case can be expressed as follow relation

$$
\left(\frac{P_{\gamma}}{P_{0}}\right)_{\mathrm{III}}=\left(\frac{P_{\gamma}}{P_{0}}\right)_{\min }+A_{\mathrm{I}} \cdot \exp \left(-k_{\mathrm{III}} \cdot D_{\gamma}\right),
$$

where

$$
\left(\frac{P_{\gamma}}{P_{0}}\right)_{\min }=\mathrm{const}
$$

This stage of the light output power decreasing of the LEDs can be clearly associated with the introduction of radiation defects. It should be particularly noted that, the probability of a catastrophic failure is sharply grown up at the third stage of LEDs emission power reduction. It is caused by the appearance of a breakage because of the disconnection of the LED crystal from the heat sink. This may indirectly indicate the overheating of the LEDs during further $W-I$ measurements.

\section{CONCLUSIONS}

In conclusion, we summarize the main research results presented in this paper.

1. The effect of the irradiation mode (without and with the separation of electron-hole pairs generated by irradiation in the built-in electric field of the $p$ - $n$ junction of the LEDs) was established in the research of light output power change of the LEDs made on the basis of the GaP single crystal structure $(\lambda=655 \mathrm{~nm})$ during irradiation by gamma quanta. Moreover, the segregation of electron-hole pairs in the field of the built-in $p$ - $n$ junction makes it possible to significantly induction stability of the LEDs.

2. The light output power reduction under gamma-quanta irradiation can be expressed by three characteristic stages. The first stage is caused by radiation-stimulated rearrangements of the first initial defect (complex of defects) of the first type. While the rearrangements of electron-hole pairs produced by gamma radiation leads to a visible shift in the radiation dose limit to the region of higher radiation doses. The shifted dose separates the first and second stages of light output power reduction. In addition, there is a slight decrease in the relative contribution of the first stage to the common decrease in LEDs emission power. At the second stage, the decrease in light output power of the LEDs is because of the radiation-produced rearrangements of the own initial defect (complex of defects) of the second type. At the same time, the dissipation of electron-hole pairs induced under irradiation leads to a significant increasing in the gamma-quanta irradiation LEDs hardness.

3. At the third stage, the reduction in the LEDs light output power is due to the intromission of radiation defects. In this case, there is also an increase in the stability of the LEDs for the case of rearrangements of electron-hole pairs generated under irradiation. This stage is limited by the development of catastrophic failures caused by the appearance of a breakage due to the disconnection (breakage) of the LED crystal from the heat sink.

4. For each of the revealed stages of LEDs light output power decreasing, empirical relations are determined. These describe the light output power change with radiation dose increasing, as well as the damage coefficients for the used irradiation modes.

5. Empirical relations and damage coefficients are determined for each of the identified stages of light output power reduction. The relations distrain the change in the LEDs emission power when radiation dose of gamma-quanta increases. 


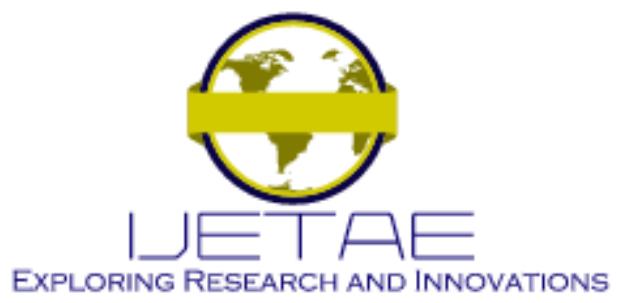

International Journal of Emerging Technology and Advanced Engineering Website: www.ijetae.com (E-ISSN 2250-2459, Scopus Indexed, ISO 9001:2008 Certified Journal, Volume 12, Issue 02, February 2022)

The research work was carried out with the support of the Development Program of the National Research Tomsk Polytechnic University.

\section{REFERENCES}

[1] Wilson D.J., Schneider K., Hönl S, Anderson M., Baumgartner Ya., Czornomaz L., Kippenberg T.J. Seidler P. Integrated gallium phosphide nonlinear photonics Nature Photonics, 2020, vol. 14, no. 1, pp. 57-62.

[2] Gontaruk, O.N., Kovalenko, A.V., Konoreva, O.V., Malyj, E.V., Petrenko, I.V., Pinkovskaya, M.B., Tartachnik, V.P. Elektrolyuminescenciya serijnyh svetodiodov GaP v zelenoj oblasti spektra [Electroluminescence of $\mathrm{GaP}$ serial LEDs in the green region of the spectrum] Zhurnal prikladnoj spektroskopii. 2013, vol. 80, no. 6, pp. 859-863 (in Russian).

[3] Turkin A. Poluprovodnikovye svetodiody: istoriya, fakty, perspektivy [Semiconductor LEDs: history, facts, prospects] Poluprovodnikovaya svetotekhnika 2011, vol. 5, no. 13, pp. 28-33 (in Russian).

[4] John S. Different Types of in Light Emitting Diodes (LED) Materials and Challenges-A Brief Review International Journal for Research in Applied Science and Engineering Technology, 2018, vol. 6, pp. 4418-4420.

[5] Kogan L.M. Svetodiody novogo pokoleniya dlya svetosignal'nyh i osvetitel'nyh priborov [New generation LEDs for lighting and lighting devices] Novosti svetotekhniki, 2001, no. 7-8, pp. 34-35 (in Russian).

[6] Bajkov V.D., Garmash A.A., Rannev N.Yu. Radiacionno-stojkij malopotreblyayushchij slozhnofunkcional'nyj blok universal'nogo sintezatora chastot 2-800 MGc s fazovoj avtopodstrojkoj chastity [Radiation-resistant low-consumption complex-functional unit of a universal frequency synthesizer 2-800 $\mathrm{MHz}$ with phase-locked frequency] Vestnik Nacional'nogo issledovatel'skogo yadernogo universiteta MIFI, 2016, vol. 5, no. 4, pp. 373-377 (in Russian).

[7] Bogolyubskij, M., Harlov, Yu., Kuryakin, A., Mamonov, A., Petrov, V., Sadovskij, S., Sen'ko, V. Arhitektura programmnogo obespecheniya svetodiodnoj monitornoj sistemy spektrometra Phos ustanovki ALICE na kollajdere LHC [Software architecture of the LED monitor system of the Phos spectrometer of the ALICE installation at the LHC collider] Vestnik nacional'nogo issledovatel'skogo yadernogo universiteta MIFI, 2013, vol. 2, no. 1, pp. 101 (in Russian).

[8] Chang M. H., Das D., Varde P.V., Pecht M. Light emitting diodes reliability review Microelectronics Reliability, 2012, vol. 52, no. 5, pp. 762-782.

[9] Brudnyi V., Prudaev I., Oleinik V., Marmaluk A Electron irradiation degradation of $\mathrm{AlGaInP} / \mathrm{GaAs}$ light-emitting diodes Physica status solidi (a), 2018, vol. 215, no. 8, pp. 1700445.
[10] Gradoboev A.V., Bondarenko E.A., Varlachev V.A., Yemets E.G., Sednev V.V. A Technique for Studying the Resistance of LEDS to Irradiation by Fast Neutrons at the IRT-T Reactor Instruments and Experimental Techniques, 2021, vol. 64, no. 4, pp. 619-622.

[11] Irha V.I. Radiacionnaya degradaciya svetoizluchayushchih diodov s pereizlucheniem fotonov[Radiation degradation of light-emitting diodes with photon re-emission] Nauchnye trudy ONAS im. AS Popova, 2018, no. 1, pp. 152-158.(in Ukrainian)

[12] Brudnyj V.N., Peshev V.V., Surzhikov A.P. Radiacionnoe defektoobrazovanie $\mathrm{v}$ elektricheskih polyah: arsenid galliya, fosfid indiya [Radiation defect formation in electric fields: gallium arsenide, indium phosphide]. Novosibirsk : Nauka, 2001. 136 p (in Russian).

[13] Brudnyj V.N., Peshev V.V. Vliyanie elektronnogo (zaryadovogo) sostoyaniya E-lovushek na effektivnost' ih nakopleniya v n-GaAs pri obluchenii [Influence of the electronic (charge) state of E-traps on the efficiency of their accumulation in $\mathrm{n}-\mathrm{GaAs}$ under irradiation] Fizika i tekhnika poluprovodnikov, 2003, vol. 37, no. 1, pp. $22-28$ (in Russian).

[14] Shubert F.E. Svetodiody [LEDs]. Moscow, 2008. 495 p (in Russian).

[15] Golovin V.S., Shashkin, I.S., Slipchenko, S.O., Pihtin, N.A., Kop'ev, P.S. Vygoranie prodol'nogo prostranstvennogo provala (LSHB) v moshchnyh poluprovodnikovyh lazerah: chislennyj analiz [Longitudinal spatial dip burnout (LSHB) in high-power semiconductor lasers: numerical analysis] Kvantovaya elektronika, 2020, vol. 50, no. 2, pp. 147-152 (in Russian).

[16] Polubavkina Yu. S., Zubov F.I., Moiseev E.I., Kryzhanovskaya N.V., Maksimov M.V., Semenova E.S., Yvind K., Asryan L.V., Zhukov A.E. Osobennosti volnovodnoj rekombinacii v lazernyh strukturah $\mathrm{s}$ asimmetrichnymi bar'ernymi sloyami [Features of waveguide recombination in laser structures with asymmetric barrier layers] Fizika i tekhnika poluprovodnikov, 2017, vol. 51, no. 2, pp. 263-268 (in Russian).

[17] Gradoboev A.V., Simonova A.V., Orlova K.N. Influence of irradiation by $60 \mathrm{Co}$ gamma-quanta on reliability of IR-LEDs based upon AlGaAs heterostructures Physica Status Solidi (C). 2016, vol. 13, no. 10-12, pp. 895-902.

[18] Gradoboev A. V., Orlova K. N., Simonova A. V. Changing the shape of watt-ampere characteristic of leds based upon gap $(\lambda=590$ nm) irradiated by gamma-quanta Materials Science Forum. 2019, vol. 970, pp. 88-99.

[19] Gradoboev, A. V., Orlova, K. N., Asanov, I. A., \& Simonova, A. V. The fast neutron irradiation influence on the AlGaAs IR-LEDs reliability Microelectronics Reliability. 2016, vol. 201665, pp. 55-59. 